\title{
A SECURITIZAÇÃO NO AGRONEGÓCIO: ANÁLISE CRÍTICA DA SECURITIZAÇÃO DE RECEBÍVEIS AGRÍCOLAS - CRA (CERTIFICADO DE RECEBÍVEIS DO AGRONEGÓCIO)
}

Dissertação apresentada ao Departamento de Direito Comercial da Faculdade de Direito da Universidade de São Paulo, como exigência parcial para a obtenção do título de Mestre em Direito, sob orientação da Professora Associada Doutora Rachel Sztajn. 


\section{BANCA EXAMINADORA:}

Orientadora: Professora Dra. Rachel Sztajn

Professor(a) Arguidor(a):

Professor(a) Arguidor(a):

Professor(a) Arguidor(a): 


\section{Agradecimentos}

À Denise, minha querida esposa e amor da minha vida, pelo carinho e motivação, essenciais para o desenvolvimento do presente trabalho.

Aos meus pais, Vanda e Márcio e à minha irmã Olívia, pelo apoio incondicional, amor e convívio que foram fundamentais para o meu crescimento pessoal.

À Professora Rachel Sztajn pela oportunidade, confiança, generosidade e constante estímulo ao conhecimento, contribindo de maneira ímpar ao desenvolvimento de seus alunos.

Aos colegas do Banco ABN AMRO, em especial ao Nicolau Nardi, pelo apoio e incentivo ao meu aprimoramento profissional.

Ao Professor Haroldo Verçosa e ao Gabriel Leutewiler pelos valiosos comentários e sugestões apresentados no exame de qualificação, que muito contribuíram para a elaboração deste trabalho. 
O mundo que você anseia pode ser conquistado. Existe, é real, é possível, é seu.

Ayn Rand 


\section{Resumo}

Algumas controvérsias cercaram e ainda cercam a emissão do Certificado de Recebíveis do Agronegócio (CRA) atraindo a atenção de reguladores e do mercado financeiro e de capitais. A discussão central gira em torno da estrutura do CRA e da análise do fenômeno do agronegócio e da cadeia agroindustrial, passando pela demonstração da mudança gradativa do paradigma do financiamento do agronegócio, de estatal para privado, sendo o CRA uma das novas fontes de funding para o setor. A análise do fenômeno do agronegócio e da cadeia agroindustrial são de fundamental importância para a interpretação da legislação aplicável aos CRAs e para a compreensão do que pode ser securitizado utilizando-se este instrumento. Examina-se ainda a estrutura de uma securitização por meio da emissão de CRAs para depois adentrar-se na anatomia deste tipo de securitização, analisando-se a função do patrimônio separado e a revolvência do lastro dos CRA. Ao final a possibilidade de indexação do CRA ao dólar norte-americano e a subsunção do CRA aos conceitos de título de crédito e valor mobiliário são exploradas. Este trabalho propõe-se a concluir sobre as alterações no panorama legal que de um lado poderiam tornar o investimento em CRA mais seguro para os investidores e de outro contribuir para incrementar os volumes de captação de recursos por meio do instrumento.

PALAVRAS CHAVE: CRA - Certificado de Recebíveis do Agronegócio - Agronegócio Cadeia Agroindustrial - Securitização - Patrimônio Separado - Revolvência - Indexação. 


\begin{abstract}
Some controversies surrounded and still surround the issuance of Agribusiness Receivables Certificates (ARC) attracting the attention of regulators and the financial and capital markets. The main discussion revolves around the structure of the ARC and the analysis of the agribusiness phenomenon and the agroindustrial chain, also demonstrating the gradual change of the agribusiness financing, from public to private, being the ARC one of the new sources of funding for the sector. The analysis of the agribusiness fenomenon and the agricultural chain are of paramount importance for the interpretation of the applicable legislation to the ARC and the understanding of the underlying assets that can be securtitized by the instrument. It is also examined the structure of a securitization through the issuance of ARCs and the anatomy of this type of securitization and the objective of the segregated assets and the revolvence of the ballast of the ARC. In the end the possibility of the indexation of the ARC to the United States Dollar and the adherence of the ARC to the concepts of title of credit and security are explored. This paper concludes on the changes in the legal framework that in one hand could make the investment in ARC saffer for the investors and on the other hand contribute for the increment of the volumes of fundraising by the instrument.
\end{abstract}

KEYWORDS: ARC - Agribusiness Receivables Certificates - Agribusiness - Agroindustrial Chain - Securitization - Segregated Assets - Revolving - Indexation. 


\section{SUMÁRIO}

INTRODUÇÃO

1.

O AGRONEGÓcIO A CADEIA AGROINDUSTRIAL E SEU 13 FINANCIAMENTO

1.1. O Agronegócio e a Cadeia Agroindustrial

1.2. Fontes de Financiamento do Agronegócio (Esgotamento das 17 Fontes Tradicionais)

1.3. Novo Paradigma: o Financiamento Privado (Insuficiência das 25 Fontes Internas de Financiamento em Reais)

1.4. Securitização como alternativa de financiamento do 26 agronegócio

1.5. A importância da compreensão do que é o Agribusiness para o 29 CRA

2. SECURITIZAÇÃO

2.1. Breve Contexto Histórico 35

2.2. Definição de Securitização e sua natureza jurídica 42

2.3. Securitização por meio de certificados de recebíveis do 48 agronegócio

2.4. Estrutura de uma Securitização por meio de Certificados de 50 Recebíveis do Agronegócio

2.4.1 As Companhias Securitizadoras de Crédito da Cadeia 50 Agroindustrial e o regime fiduciário

2.4.2 O Contrato de Cessão

2.4.3 O Termo de Securitização 51

3. FUNÇÃO JURÍDICO-ECONÔMICA DO PATRIMÔNIO 53 SEPARADO

3.1. Conceito Legal e Objetivo do Patrimônio Separado 53

3.2. O Patrimônio Separado em uma securitização de CRA 56 
3.3. Seria o patrimônio separado em uma emissão de CRA instituto 58 com função juridico-econômica similar a que instituto do direito brasileiro?

4. REVOLVÊNCIA DO LASTRO DOS CERTIFICADOS DE 61 RECEBÍVEIS DO AGRONEGÓCIO

4.1. Conceito

4.2. Importância 62

$\begin{array}{lll}\text { 4.3. Riscos para o Investidor } & 63\end{array}$

4.4. Parâmetros Propostos para a Operacionalização da Revolvência 64

4.4.1 Processo CVM n RJ 2013/8860 64

4.4.2 Edital de Audiência Pública SDM nº 01/2017 (antecedente 66 inalterado da Instrução CVM número 600/2018)

4.5. Análise Critica do Processo de Revolvência 71

5. CERTIFICADOS DE RECEBÍVEIS DO AGRONEGÓCIO 73 INDEXADOS AO DÓLAR

5.1. Racional econômico para a indexação 73

5.2. Legalidade para a Indexação - Contexto Histórico e Legislação 73 Envolvendo Curso e Indexação em Moeda Estrangeira

5.3. Da possibilidade de indexação de CRA a moeda estrangeira 76

5.4. Da Necessidade de um quadro normativo seguro para a 81 implantação

5.5. Entraves Legais para a Operacionalização 85

6. OS CERTIFICADOS DE RECEBÍVEIS DO AGRONEGÓCIO 88 SÃO TÍTULOS DE CRÉDITO OU VALORES MOBILIÁRIOS?

6.1. Análise dos Princípios Aplicáveis aos Títulos de Crédito e sua 88 Definição

6.2. Análise dos Princípios Aplicáveis aos Valores Mobiliários e sua 92 Definição

6.3. Classificação dos Certificados de Recebíveis do Agronegócio 102 
REFERÊNCIAS BIBLIOGRÁFICAS 


\section{INTRODUÇÃO}

O agronegócio desempenha uma função fundamental para a humanidade, pois é a principal atividade que provê os alimentos necessários à subsistência da espécie humana. Além desta função, o setor é um componente cada vez mais importante da economia do nosso país, respondendo por aproximadamente $23 \%$ do Produto Interno Bruto (PIB) brasileiro1.

Vivemos em um mundo no qual o paradigma da subsistência foi superado uma vez que os mercados consumidores estão muito distantes dos mercados produtores e ocorre crescimento contínuo da população mundial. O Brasil possui vastas áreas agricultáveis em seu território, algumas delas já utilizadas e outras ainda preservadas. A vocação do nosso país para a produção de alimentos, seja para consumo interno ou para a exportação, é clara e é uma excelente oportunidade comercial, portanto, deve ser explorada e desenvolvida.

As projeções do agronegócio elaboradas pela Secretaria de Política Agrícola do Ministério da Agricultura, Pecuária e Abastecimento indicam que a produção de grãos ${ }^{2}$ deverá passar de 232,6 milhões de toneladas em 2017/2018 para 302 milhões de toneladas em 2027/28. Isso indica um acréscimo de 69 milhões de toneladas na produção atual do Brasil. Em valores relativos, representa um acréscimo de $29,8 \%$, ou uma taxa anual de crescimento de $2,5 \%$. A área de grãos deve expandir-se dos atuais 61 milhões de hectares para 71 milhões de hectares em 2027/28. ${ }^{3}$

O financiamento é um instrumento fundamental para o desenvolvimento de qualquer setor, mas é especialmente necessário em setores que possuem descasamentos entre o fluxo de consumo de recursos necessários à produção e o fluxo de sua renda. Essa é a realidade do mundo agro tendo em vista seu caráter

\footnotetext{
${ }^{1}$ Revista de Política Agrícola nº 2, 2018, Ano XXVII - No 2 - Abr./Maio/Jun. 2018, disponível em http://www.agricultura.gov.br/assuntos/politica-agricola/todas-publicacoes-de-politicaagricola/revista-de-politica-agricola/revista-de-politica-agricola-no-2-2018/view acessado em 18 de dezembro de 2018, p.6.

${ }^{2}$ Grãos: corresponde a relação das lavouras levantadas pela Conab em seus levantamentos de safras (algodão caroço, amendoim total, arroz, aveia, canola, centeio, cevada, feijão total, girassol, mamona, milho total, soja, sorgo, trigo e triticale)

${ }^{3}$ Brasil. Ministério da Agricultura, Pecuária e Abastecimento. Projeções do Agronegócio: Brasil 2017/18 a 2027/28 projeções de longo prazo / Ministério da Agricultura, Pecuária e Abastecimento. Secretaria de Política Agrícola. - Brasília: MAPA/ACE, 2018. p.112
} 
sazonal.

Com o objetivo de fomentar o financiamento do agronegócio pelo setor privado, o poder executivo decidiu editar a Medida Provisória $n^{\circ} 221$, de $1^{\circ}$ de outubro de 2004 que, dentre outros assuntos, dispunha sobre o Certificado de Depósito Agropecuário - CDA, o Warrant Agropecuário - WA, o Certificado de Direitos Creditórios do Agronegócio - CDCA, a Letra de Crédito do Agronegócio LCA e o Certificado de Recebíveis do Agronegócio - CRA ("CRA"). Posteriormente tal medida provisória foi convertida na Lei $n^{\circ} 11.076$, de 30 de dezembro de 2004 (“Lei 11.076").

Após a edição da Lei 11.076 uma das formas de obtenção de crédito que mais tem sido utilizada pelos membros da cadeia agroindustrial é o CRA que, quando emitido por meio de oferta pública, é também regulado pela Instrução CVM $\mathrm{n}^{\circ} 600$, de $1^{\circ}$ de agosto de 2018 (“ICVM 600”).

Anteriormente à edição da ICVM 600, os CRAs eram regulados pelas normas aplicáveis aos Certificados de Recebíveis Imobiliários, no que couber, conforme o Comunicado CRA emitido pela Comissão de Valores Mobiliários em reunião do Colegiado realizada em 18 de novembro de 2008. Quando da emissão de supracitado comunicado, a Comissão de Valores Mobiliários ressalvou que analisaria, no futuro, a necessidade de se editar regulamentação específica sobre os CRA.

A edição do comunicado mencionado acima não foi suficiente para resolver as diversas polêmicas envolvendo o instrumento, o que resultou no enfrentamento pelo colegiado da Comissão de Valores Mobiliários de inúmeras questões a respeito dos CRA que não possuíam previsão legal na regulamentação vigente à época (normas aplicáveis aos Certificados de Recebíveis Imobiliários).

As principais polêmicas discutidas e que vinham sendo objeto de atenção e preocupação do mercado financeiro e de capitais, estão relacionadas com o lastro dos CRAs, sobretudo discussões a respeito do que pode ser securitizado e quais são os parâmetros para a revolvência do lastro dos CRAs. Questionava-se se a alteração do lastro dos CRAs coadunava-se com a natureza e finalidade do título ou se importava em um desvirtuamento.

Os membros do Colegiado da CVM proferiram, no final de novembro de 2013, entendimento de que a revolvência dos CRA era possível se fossem 
observados determinados parâmetros ${ }^{4}$.

Diante desse cenário, a Comissão de Valores Mobiliários, juntamente com um esforço conjunto de diversas entidades do mercado, elaborou uma regulamentação específica para os $\mathrm{CRA}$.

A edição da ICVM 600 pacificou os temas da possibilidade da realização da revolvência do lastro dos CRA e do que pode ser considerado como lastro das emissões, mas trouxe algumas outras polêmicas que serão discutidas neste trabalho.

Uma importante distinção temática que deve ser feita é que o agronegócio não pode ser confundido com o direito fundiário e, por conseguinte, com a sua base legal - o Estatuto da Terra, Lei no 4.504, de 30 e novembro de 1964.

$O$ aludido marco legal destina-se a regular os direitos e obrigações concernentes aos bens imóveis rurais, para os fins da execução da Reforma Agrária e promoção da Política Agrícola. Definindo: (i) Reforma Agrária como o conjunto de medidas que visam a promover melhor distribuição da terra, mediante modificações no regime de sua posse e uso, a fim de atender aos princípios de justiça social e ao aumento de produtividade, e (ii) Política Agrícola como o conjunto de providências de amparo à propriedade da terra, que se destinam a orientar, no interesse da economia rural, as atividades agropecuárias, seja no sentido de garantir-lhes o pleno emprego, seja no de harmonizá-las com o processo de industrialização do país.

Observa-se que o enfoque do Estatuto da Terra está sempre ligado à propriedade do imóvel onde são realizadas as atividades agropecuárias e não a produção agropecuária realizada nas propriedades rurais.

O agronegócio está relacionado com a produção de alimentos, dos frutos que são retirados da terra diretamente pelo homem, ou lá cultivados, para alimentar animais como no caso da pecuária, suinocultura, avicultura. Dessa forma há um descolamento entre a temática fundiária e a temática do agronegócio.

O tema deste estudo mostra-se atual e relevante, não só do ponto de vista acadêmico, quanto prático, especialmente diante do expressivo crescimento do volume de emissão de CRA no mercado doméstico.

\footnotetext{
${ }^{4} \mathrm{O}$ tema da estruturação de CRA com revolvência dos direitos creditórios vinculados foi tratado pelo Colegiado da CVM em reunião datada de 26/11/2013, no âmbito do Processo CVM no RJ-20138860, que à época deliberou favoravelmente à referida possibilidade.
} 


\section{CONCLUSÃO}

O CRA é um instrumento financeiro que foi concebido e denominado como título de crédito pelo legislador e a ele foi outorgado um benefício fiscal para uma finalidade específica, qual seja - o fomento do financiamento do agronegócio.

As atividades financiáveis delimitadas pela Lei $11.076^{116}$ frequentemente entravam em conflito com o que era interpretado como agronegócio pelos participantes do mercado financeiro e membros da cadeia agroindustrial. Tendo em vista este contexto de conflito acerca das possibilidades de enquadramento de situações práticas nas hipóteses de financiamento legalmente previstas na legislação, as partes envolvidas na operação, comumente adotavam a interpretação mais restritiva acerca da subsunção da operação em questão à legislação. Essa reação é natural tendo em vista estarmos tratando de instrumento financeiro ao qual foi conferido um benefício fiscal.

Algumas emissões com interpretações mais extensivas a respeito de quais atividades estariam compreendidas no conceito legal de atividades financiáveis, foram discutidas pelo Colegiado da CVM e avaliadas pela procuradoria federal especializada que atua junto à $\mathrm{CVM}^{117}$. Essas discussões acabaram por dividir o Colegiado da CVM, e mesmo com uma manifestação desfavorável da área técnica ${ }^{118}$, o registro da operação foi deferido pelo Colegiado da CVM. Essa discussão girou em torno da adoção ou não de uma interpretação mais extensiva a respeito do tipo de recebível que poderia ser objeto de securitização nos termos da Lei 11.076.

Estas discussões foram a sinalização de que eventual instrução normativa que viria a regular a oferta pública dos CRAs adotaria a mesma vertente (expansão do conceito de atividades financiáveis pelos instrumentos criados pela Lei 11.076), o que de fato se materializou. Essa alteração legislativa reconhece a realidade,

\footnotetext{
116 Art. 23. Ficam instituídos os seguintes títulos de crédito: (...) III - Certificado de Recebíveis do Agronegócio - CRA.§ $1^{\circ}$ Os títulos de crédito de que trata este artigo são vinculados a direitos creditórios originários de negócios realizados entre produtores rurais, ou suas cooperativas, e terceiros, inclusive financiamentos ou empréstimos, relacionados com a produção, a comercialização, o beneficiamento ou a industrialização de produtos ou insumos agropecuários ou de máquinas e implementos utilizados na atividade agropecuária.
}

117 Proc. SEI 19957.001669/2016-13

118 Memorando n 61/2016-CVM/SRE/GER-1 
reverenciando o entendimento de que os elos da cadeia agroindustrial são interdependentes e, que se um deles se romper, os demais elos também serão afetados de maneira adversa. Dessa forma é pertinente que o financiamento seja extensível a todos os membros da cadeia agroinsdustrial de forma a contribuir para o seu desenvolvimento como um todo.

A questão da discussão travada no presente trabalho acerca da definição legal de que o CRA é um título de crédito, tem importância na medida em que este entendimento contribui para a desinformação e em nada ajuda na compreensão do instituto vis-à-vis a natureza do CRA se opor à natureza dos títulos de crédito, dessa forma entendemos que seria mais conveniente o legislador tê-lo classificado como título executivo extrajudicial.

Na nossa visão esta é a melhor opção tendo em vista que o CRA não se subsume à clássica definição de Cesare Vivante, uma vez que não é documento necessário para o exercício do direito literal e autônomo nele mencionado, haja vista depender, para tanto, dos direitos creditórios subjacentes à sua emissão. Além disso, grande parte dos requisitos inerentes aos títulos de crédito não são observados nos CRAs como cartularidade, literalidade, autonomia, independência e abstração.

Outros pontos discutidos no trabalho que estão relacionados com a mecânica de funcionamento de uma securitização por meio de CRA são a revolvência, função do patrimônio separado e a possibilidade da emissão de CRA indexado ao dólar, carecem de uma análise mais detalhada por parte do legislador.

A questão da revolvência, da forma como foi estruturada na ICVM 600 permite que sejam conferidos à securitizadora poderes bastante amplos para a aquisição de novos direitos creditórios do agronegócio, que podem se aproximar bastante aos poderes conferidos aos gestores autorizados pela CVM ao exercício da atividade de administração de recursos de terceiros nos termos da Instrução CVM n 558, de 26 de março de 2015. A concessão de poderes tão amplos definitivamente não foi o intuito da autarquia quando da promulgação da legislação aplicável às ofestas públicas de CRA, no que diz respeito às normas procedimentais. A pretensão sempre foi a de manter as atividades da securitizadora passivas. Este ponto tem o potencial de se tornar um problema, caso as condições de cessão e os critérios de elegibilidade presentes na documentação da operação de emissão de CRA, permitam que a securitizadora adote um papel mais ativo na 
aquisição de direitos creditórios, dessa forma seria recomendável ajuste na norma para que a questão seja explicitada.

A função do patrimônio separado no caso das emissões de CRA deve ser a de mero veículo para o recebimento dos direitos creditórios do agronegócio, um meio de passagem que detém a propriedade dos direitos creditórios do agronegócio em benefício dos titulares dos CRAs, além de receber o produto de sua liquidação repassando-os diretamente aos titulares dos CRAs. O patrimônio separado deve ser entendido como meio neutro para a recepção de direitos creditórios e recursos provenientes da liquidação de aludidos direitos. Além disso, a questão da impossibilidade de se tributar recursos do patrimônio separado deveria ser explicitada, de forma a afastar qualquer pretensão tributária por parte do fisco. Atualmente, um lastro bastante comum para operações de securitização são as debêntures, cujo rendimento integra a remuneração dos CRAs, não havendo qualquer permissivo legal que desobrigue a securitizadora de efetuar 0 recolhimento da tributação aplicável aos juros do aludido investimento.

Entende-se que a questão da indexação do CRA ao dólar, como mencionado no presente trabalho, é passível de ser construída, tendo em vista o panorama normativo que temos hoje. A questão mais problemática seria outra: o ponto da tributação de eventual ganho em reais apurado pelo investidor estrangeiro. Sob o ponto de vista do investidor estrangeiro, a variação cambial de um investimento indexado ao dólar é irrelevante, tendo em vista que isso não significa um acréscimo patrimonial para ele. Somente a incidência de remuneração sobre o valor indexado possui a capacidade de enriquecer o investidor e, portanto, seria passível de ser tributada. Dessa forma, são necessárias regras que governem essa questão para que investidores estrangeiros, que estão dispostos a correrem o risco de crédito de contrapartes brasileiras, mas não risco cambial de nossa moeda, possam utilizar o CRA como um veículo de investimento no Brasil.

A engenharia jurídica pode ser aplicada de forma a aparar algumas das arestas que ainda pairam sob as emissões de CRA, entretanto, muitos destes riscos somente podem ser mitigados, não eliminados pelos operadores do direito, de forma que, a melhor maneira de se endereçá-los, seria por meio de alteração legislativa.

A alteração na legislação seria medida que teria o potencial de fomentar o incremento das emissões (podendo-se contar com o funding em dólares, por 
exemplo) e solucionar riscos regulatórios e fiscais aos quais os investidores de CRA ainda estão sujeitos e que, muitas vezes, chegam até mesmo a inviabilizar operações, ou expor os investidores a riscos que desconhecem ou não têm condições de avaliar. Ademais, a experiência mostra que essa proteção transcende o interesse direto e imediato dos investidores, compondo um instrumento de resguardo à economia nacional, algo que a mera inserção de um fator de risco no prospecto de uma oferta pública não resolve. 


\section{REFERÊNCIAS BIBLIOGRAFICAS}

ASCARELLI, Tullio. Problemas das sociedades anônimas e direito comparado. São Paulo: Saraiva. 1969.

. Teoria Geral dos Títulos de Crédito. Campinas, SP: Servanda Editora, 2009.

AVELINO, Luiz Filipi de Cristofaro. Aspectos Jurídicos da Securitização no Brasil, Dissertação de Mestrado. Faculdade de Direito da USP. São Paulo: 2014. AZEVEDO, Antônio Junqueira de. Negócio jurídico: existência, validade e eficácia. 4. ed. São Paulo: Editora Saraiva, 2002.

Barreto Filho, Oscar. Teoria do estabelecimento comercial: fundo de comércio ou fazenda mercantil. São Paulo: Max Limonad, 1969. In: CAMINHA, Uinie. A Securitizaçao. Função econômica e regime jurídico. Tese de Doutorado apresentada ao Departamento de Direito Comercial da Faculdade de Direito da USP. Orientadora: Prof. Dra. Rachel Sztajn. São Paulo, 2004.

BESKOW, Paulo Roberto. O crédito rural público numa economia em transformação: criação e início do funcionamento das atividades de financiamento agropecuário da Carteira de Crédito Agrícola e Industrial (CREAI), do Banco do Brasil (BB) - 1937 a 1945. Revista Eletrônica de História do Brasil. Juiz de Fora, volume 9, número 1, jan-jun, 2007.

BRASIL. Ministério da Agricultura, Pecuária e Abastecimento. Projeções do Agronegócio: Brasil 2017/18 a 2027/28 projeções de longo prazo / Ministério da Agricultura, Pecuária e Abastecimento. Secretaria de Política Agrícola. Brasília: MAPA/ACE, 2018.

BOBBIO, Norberto. Teoria do Ordenamento Jurídico. São Paulo: Editora Polis, 1991

BULGARELLI, Waldirio. Títulos de crédito. 16. ed. São Paulo: Atlas, 2000.

BURANELLO, Renato M. Manual do Direito do Agronegócio. São Paulo: Saraiva, 2013.

Sistema Privado de Financiamento do Agronegócio -

Regime Jurídico. 2. ed. rev., atual. e ampl. São Paulo: Quartier Latin, 2011.

CAMINHA, Uinie. A Securitização Função Econômica e Regime Jurídico. Tese de Doutorado. Faculdade de Direito da USP. São Paulo: 2004.

CARVALHOSA, Modesto. Comentários à Lei de Sociedades Anônimas. v. I. 
Saraiva: São Paulo, 2009.

CERQUEIRA, Bruno Saraiva Pedreira de. Finanças Corporativas: aspectos jurídicos e estratégicos. (Coord. Sérgio Botrel, Henrique Barbosa) 1. ed. São Paulo: Editora Atlas, 2016.

CHAVES, Natália Cristina. Direito empresarial: securitização de crédito. Belo Horizonte: Editora Del Rey, 2006.

COMPARATO, Fabio Konder. Novos Ensaios e pareceres de direito empresarial. Rio de Janeiro: Forense, 1981.

DAVIS, John H.; GOLDBERG, Ray A. A concept of agribusiness. Division of research, Graduate School of Business Administration, Harvard University, 1957.

DELFIM NETTO, Antônio. O Problema do Café no Brasil. São Paulo: Instituto de Pesquisas Econômicas, 1981

DIAS, Guilherme L. da S.; Mobilização de poupança e o financiamento do setor agrícola. Piracicaba: ESALQ-USP, 1995, p. 16.

FERRARA, Francesco. A simulação dos negócios jurídicos. São Paulo, Saraiva \& Cia., 1939. In: CAMINHA, Uinie. A Securitizaçao. Função econômica e regime jurídico. Tese de Doutorado apresentada ao Departamento de Direito Comercial da Faculdade de Direito da USP. Orientadora: Prof. Dra. Rachel Sztajn. São Paulo, 2004.

Gomes, Orlando. Contratos. 26. ed. Rio de Janeiro: Editora Forense, 2007. Introdução ao direito civil. 10a ed. Rio de Janeiro: Forense, 1991.

KENDALL, Leon T.; FISHMAN, Michael J. A Primer on Securitization. Mass.: MIT Press, 1996.

LEÃES, Luiz Gastão Paes de Barros. O conceito de security` no direito norteamericano e o conceito análogo no Direito Brasileiro. Revista de Direito Mercantil, Industrial, Econômico e Financeiro, São Paulo: Revista dos Tribunais, n. 14 , p. $41-60,1974$

LEUTEWILER, Gabriel Buscarini. O ordenamento normativo dos sistemas agroindustriais. Tese de Doutorado apresentada ao Departamento de Direito Comercial da Faculdade de Direito da USP. Orientadora: Prof. Dra. Rachel Sztajn. São Paulo, 2015

LOSANO, Mario G. Sistema e estrutura no direito: das origens à escola histórica. São Paulo: Martins Fontes, 2008, vol. I. 
LUCCA, Newton de. A Cambial-Extrato. São Paulo: Revista dos Tribunais, 1985. MARCONDES MACHADO, Sylvio. Limitação de responsabilidade de comerciante individual. São Paulo: Max Limonad, 1956.

MARCONDES MACHADO, Sylvio. Problemas de direito mercantil. São Paulo: Max Limonad, 1970. In: CAMINHA, Uinie. A Securitizaçao. Função econômica e regime jurídico. Tese de Doutorado apresentada ao Departamento de Direito Comercial da Faculdade de Direito da USP. Orientadora: Prof. Dra. Rachel Sztajn. São Paulo, 2004.

MASSUQUETTI, Angélica. A mudança no padrão de financiamento da agricultura brasileira no período 1965-97. 1998. Monografia apresentada à Universidade Rio Grande do Sul.

MASSUQUETTI, A.; SOUZA, O. T. ; BEROLDT, L. . Instrumentos de política agrícola e mudanças institucionais. In: $48^{\circ}$ Congresso da Sociedade Brasileira de Economia, Administração e Sociologia Rural (SOBER), 2010, Campo Grande (MS). Anais do $48^{\circ}$ Congresso da Sociedade Brasileira de Economia, Administração e Sociologia Rural (SOBER). Piracicaba (SP): SOBER, 2010.

MATTOS FILHO, Ary Oswaldo. O conceito de valor mobiliário. Revista de Direito Mercantil, Industrial, Econômico e Financeiro, São Paulo: Revista dos Tribunais, n. 59 , p. $30-55,1985$

MESSINEO Tiloli di Crédito, p. 8, in Ascarelli, Túlio. Teoria Geral dos Títulos de Crédito / Tullio Ascarelli. - Campinas, SP: Servanda Editora, 2009.

MORVAN, Y. Filière de Production. In: Fondaments d'economie industrielle. Paris: Economica, 1985. apud ZYLBERSZTAJN, Decio. Estruturas de Governança e Coordenação do Agribusiness: Uma Aplicação da Nova Economia das Instituições. Tese (Livre Docência) apresentada ao Departamento de Administração da Faculdade de Economia, Administração e Contabilidade da Universidade de São Paulo, São Paulo, 2005

NASCIMENTO, Andressa Fernanda do; PIZAIA, Marcia Gonçalves; CAMARA, Marcia Regina Gabardo. Fontes de Financiamento da Agricultura Brasileira. XLV Congresso da Sociedade Brasileira de Economia, Administração e Sociologia Rural - SOBER. 22-25 jul. 2017. Londrina - PR.

NORONHA, Najjarian, ILENE, Patrícia de. Securitização de Recebíveis Mercantis. São Paulo: Quartier Latin, 2010.

ODITAH, Fidelis. Selected issues in securitization. In: The Future for the global 
securities market: legal and regulatory aspects. Oxford: Clarendon Press, 1996. P. 84. In: CAMINHA, Uinie. A Securitizaçao. Função econômica e regime jurídico. Tese de Doutorado apresentada ao Departamento de Direito Comercial da Faculdade de Direito da USP. Orientadora: Prof. Dra. Rachel Sztajn. São Paulo, 2004.

PICKERT, Kate. A Brief History of Fannie Mae and Freddie Mac. Time Magazine. Disponível

em:

$<$ http://content.time.com/time/business/article/0,8599,1822766,00.html>. Acesso em: 02 maio 2017.

PONTES DE MIRANDA, Francisco Cavalcanti, Tratado de direito privado, 3a ed., Rio de Janeiro: Borsoi, 1970, t. V.

REVISTA de Política Agrícola n 2, 2018, Ano XXVII - No 2 - Abr./Maio/Jun. 2018. ROSA JÚNIOR, Luiz Emygdio Franco da. Títulos de Crédito.4. Ed. Revista e atualizada, de acordo com o novo Código Civil - Rio de Janeiro: Renovar, 2006.

SALOMÃO NETO, Eduardo. O Trust e o Direito Brasileiro. São Paulo, Trevisan, 2016.

SERRA, José. Ciclos e mudanças estruturais na economia brasileira do pósguerra. In: BELLUZZO, Luiz G. de M.; COUTINHO, Renata (org.). Desenvolvimento capitalista no Brasil: ensaios sobre a crise. 2. ed. São Paulo: Brasiliense, 1983, v.1 STEVEN T. Sonka. MICHAEL A. Hudson. Why Agribusiness Anyway? Agribusiness, Vol. 5, No. 4, 305-314 (1989). John Wiley \& Sons, Inc.

VIVANTE, Cesare. Instituições de Direito Comercial. 1910, editor Lisboa Teixeira. ZYLBERSZTAJN (Estruturas de Governança e Coordenação do Agribusiness: Uma Aplicação da Nova Economia das Instituições. Tese (Livre Docência) apresentada ao Departamento de Administração da Faculdade de Economia, Administração e Contabilidade da Universidade de São Paulo, São Paulo, 2005 